\title{
Implementation of a methodology to design evaluation models in Technology Transfer projects
}

\begin{abstract}
This document introduces the implementation and development of a methodology for the establishment of an assessment model used by COTECMAR and the Colombian National Navy (Armada Nacional de Colombia), which allows for the valuation of different strategies or routes in technology transfer projects that are in conceptual or definition phase. This model contains different attributes that may be parametrized, according to the ponderation of the variables that represent the development of a project. In addition, the application of this model, allows for the decision-making process to be assessed quantitatively, based on the best relation between the effectiveness measures, cost and risk.
\end{abstract}

Key words: assessment models, measurement of performance, effectiveness, cost, risk, technology transfer, naval system.

\section{Resumen}

Este documento presenta la aplicación y el desarrollo de una metodología para la elaboración de un modelo de evaluación empleado por COTECMAR y la Armada Nacional de Colombia, que permita valorar diferentes estrategias o rutas en proyectos de transferencia tecnológica que se encuentren en fase de definición o conceptual. Este modelo, se compone de atributos disimiles que pueden ser parametrizables, acorde a la ponderación de las variables que representan el desarrollo de un proyecto. Además, la aplicación de este modelo permite la toma de decisiones valorada cuantitativamente, basada en la mejor relación de las medidas de efectividad, costo y riesgo.

Palabras claves: Modelo de evaluación, medida de desempeño, efectividad, costo, riesgo, transferencia tecnológica, sistema naval.

Date Received: October 27 2016 - Fecha de recepción: Octubre 27 de 2016

Date Accepted: December 15 2016 - Fecha de aceptación: Diciembre 15 de 2016

\footnotetext{
${ }^{1}$ Mechatronic Engineer, M.Sc. Electronic Engineering, COTECMAR Researcher. Cartagena, Colombia. Email: iran. vdiaz@cotecmar.com

${ }^{2}$ Naval Engineer - Sp. Electronics, Master Defense Technologies, Chief of R+D department at COTECMAR, Cartagena, Colombia. Email: wcastro@cotecmar.com

${ }^{3}$ Electronic Engineer, M.Sc. Electronic Engineering, COTECMAR Researcher. Cartagena, Colombia. Email: smarrugo@cotecmar.com
} 


\section{Introduction}

Designing an assessment model that allows for decision making, based on the cost-efficiency-risk relationship, is a challenge for those who evaluate alternatives that lead to the solution of a Project or an important action within an organization.

The designed model evaluates three (03) dimensions, which through their correlation, support decision-making:

- Effectiveness in the fulfillment of the objectives of the project.

- Project development cost and integrated logistic support of the naval system.

- Assessed risk from the perspectives of scope, timeline and cost.

Each one of these measures is obtained through the application of an effectiveness, risk and cost model respectively. The methodology used to define these models in relation with the selection of the different alternatives for the development of the Project is described below.

\section{Methodology to evaluate Effectiveness}

Fig. 1 presents a general view of the different phases of the model, which allows to obtain an Overall Measurement Of Effectiveness (OMOE) [2], which is acquired for each selection alternative. The following premises are required for the development of the project:

- The operational includes operation, maintenance, and integrated logistic support of the system to be developed.

- The operational capacities required include the high-level functionalities which must provide the solution and capacities to develop in order to extend the life cycle.

- The Measures of Performance (MOP), are weighted values of the different capacities and functionalities to be assessed in the model.

- The technological Options, value curves and weighing of the MOPs are criteria that may be quantifiable according to their nature. These criteria are described in the application of the model.

Fig. 1. Stages in the effectiveness model

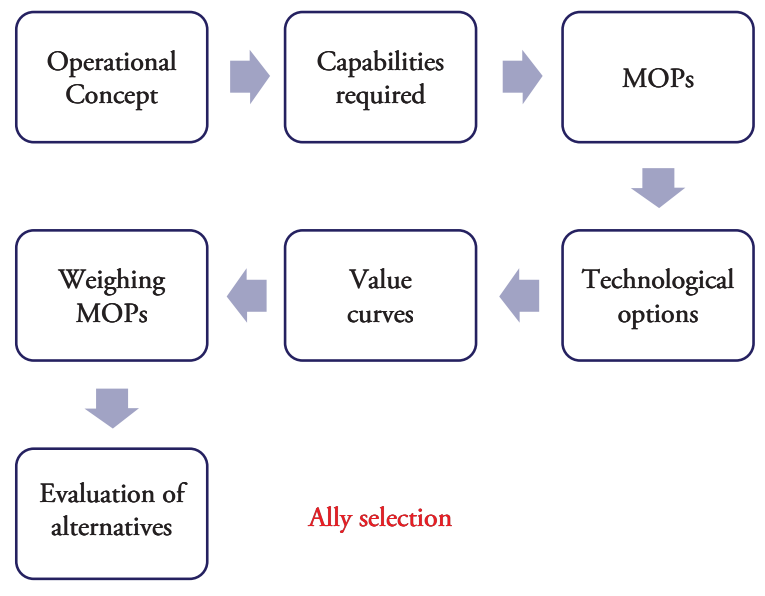

\section{Risk Assessment Methodology}

Fig. 2, presents the general outline of risk events, associated to the Overall Measurement of Risk (OMOR). The evaluation of risks associated to performance, cost, and timeline is done through the identification, analysis and priorization of adverse effects to the Project, considering their impact, and occurrence probability.

Per [3], this type of risk assessment is greatly important during the phases of exploration and conceptual design of a Project, or when considering new technologies, unique processes and new concepts.

Fig. 2. Stages of the risk model

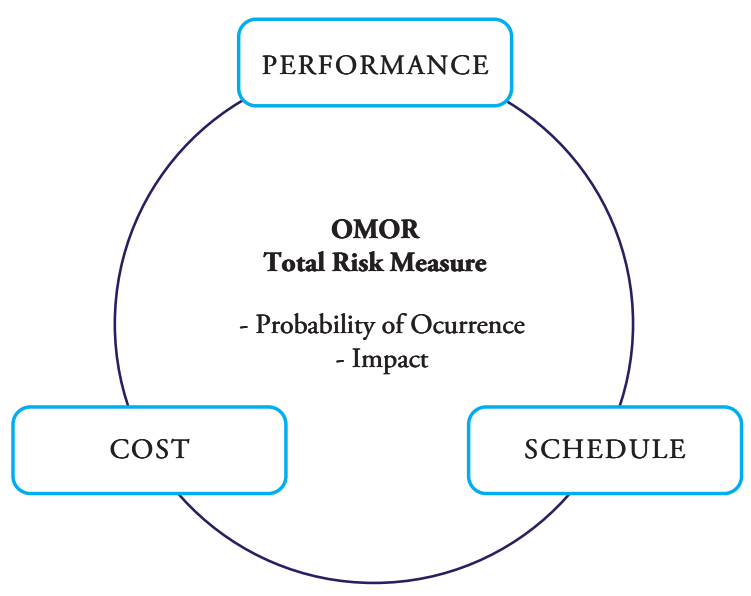


The development methodology for this model is based on the following procedure:

- Identify potential areas of risk and events associated to each one of them.

- Assign probabilities of Occurrence (Pi) and impacts $(\mathrm{Ci})$ associated to each risk event (Ei).

- Define the function of the Overall Measurement Of Risk (OMOR).

\section{Methodology to evaluate Cost}

Fig. 3 shows the general outline of the main components of cost, associated to the Overall Measurement Of Cost (OMOC). The result of this evaluation will show the equivalent value (cost) for each alternative or proposal, including specific costs and additional COTECMAR-ARC costs, associated to each one of the alternatives.

To obtain the OMOC measurement, the costs associated to the development of the system are first identified, which implies the identification of the required association: supplier, ally, or contractor, and inclusion of the required costs for the development of the project (association cost). Likewise, the input (goods) and services, personnel and indirect costs associated to participation (participation costs), required are also related.

Additionally, the costs associated to Integrated Logistic Support, where the costs required to guarantee the life cycle of the system (cost of life cycle) are also identified.

Fig. 3. Main components of the cost evaluation model

$\left.\left.\sum \begin{array}{c}\text { Costo of } \\ \text { Association }\end{array} \geqslant \begin{array}{c}\text { Cost of } \\ \text { participation }\end{array}\right\rangle \begin{array}{c}\text { Life cycle } \\ \text { cost }\end{array}\right\rangle$

\section{Implementation of the methodology}

The following is a description of the model obtained as of the implementation of the methodology presented above.

\section{Effectiveness Model}

As of the operational concept, the first Group of experts, identifies the required capacities to achieve success in the execution of the project:

- Functional capacities of the system

- Technical capacities of the system

- Integration capacity of the system

- Capacity to manage the life cycle of the system

Each one of these categories is associates to an affinity group ${ }^{1}$ in the assessment model. In this case four (4) groups were identified:

- Technology Transfer (ToT): groups the most significant aspects associated to transfer of knowledge and Know How, which will be evaluated from the proposals.

- System Coverage: groups the aspects associated to the types of units and desired quantities for the system prototypes.

- Integration Level: groups the relevant aspects, associated to the minimum requirements desired for integration and interconnection at a system level and its relation with existing systems in each unit.

- Functionalities: groups aspects associated to function, profit, and operation capacities of the system, per the operational needs of the ARC.

Fig. 4 presents the general outline of the effectiveness model, where the association between affinity groups, the performance measurements and the quantitative measurement of alternatives may be seen. In the same way, the capacities to be obtained by ARC and COTECMAR during the development of the project, may also be seen.

Different MOPs are determined for each affinity model, which are divided into two groups: qualified and quantified. Quantified are those associated to numerical values within the model, while qualified, are those MOPs that are not directly measurable, therefore, making it necessary

\footnotetext{
1 The affinity groups are a set of performance measurements
} considered to evaluate each one of the alternatives. 
Fig. 4. Histogram of ballast water reception tanks

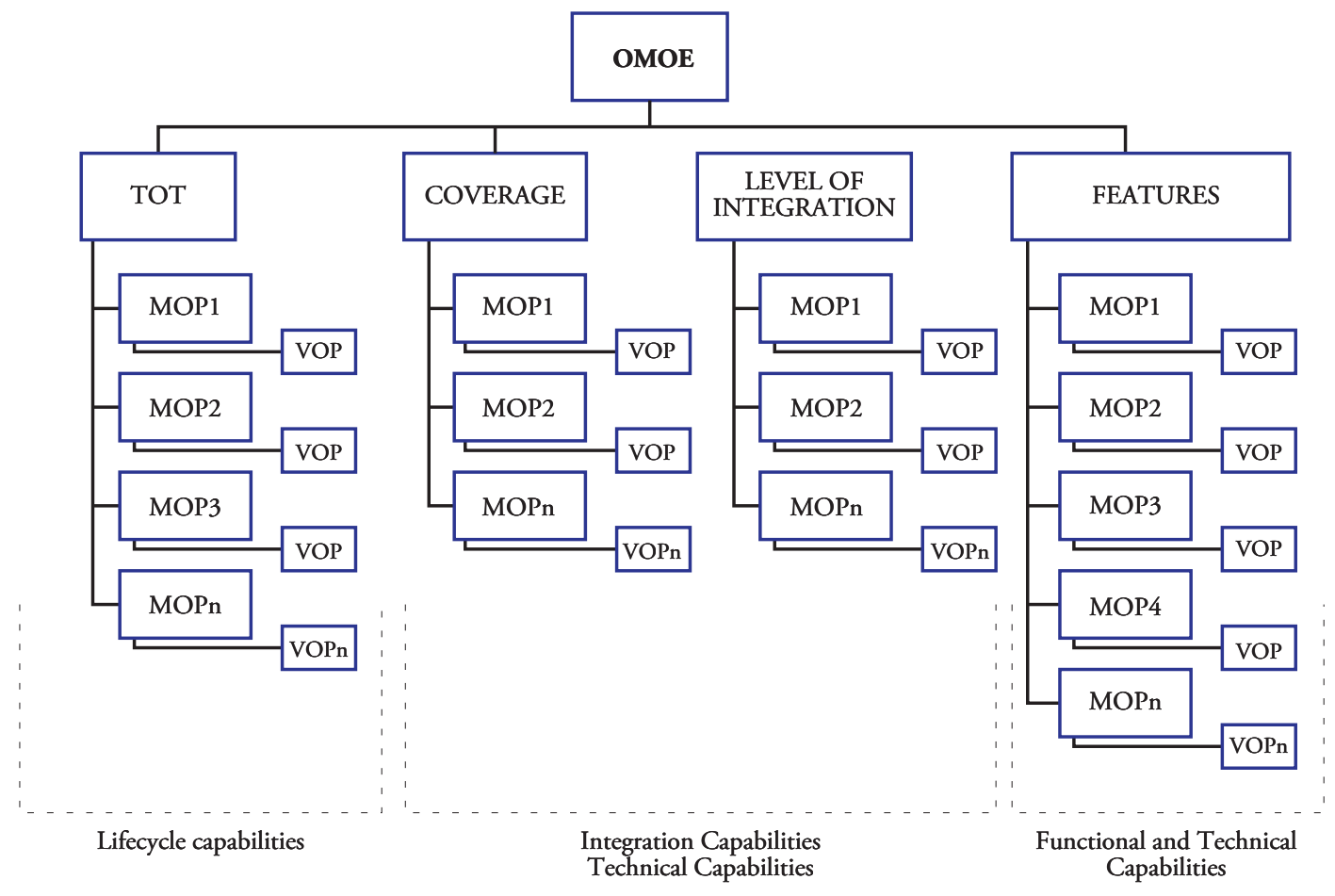

to consider options or technological alternatives that may be numerically evaluated and that allow for the evaluation of the presented proposals.

A continuous o discrete value curve is selected for each one of the technological options proposed. Their corresponding superior and inferior limits are suggested for the case of continuous curves and ponderations in the case of discrete curves.

The ponderation of the different MOPs is done by the first Group of experts, as of the cross-check of pairs, taking as a reference model the AHP methodology. This weighing allows to identify the level of relevance of a MOP compared to another and to translate this importance into a coefficient or numerical value. This relationship is seen by:

$M O E=w_{1} * M O P_{1}+w_{2} * M O P_{2} \ldots w_{n} * M O P_{n}$

\section{Risk Model}

Taking as reference what was established in [3], the different areas of risk stated below are defined:
- Threat

- Requirements

- Design

- Test and evaluation

- Simulation

- Technology

- Logistics

- Production/capacity

- Concurrence

- Capacity of the developer

- Cost of technology/financing

- Schedule/timeline

- Technology management

Although these areas are not the only ones applicable to the type of Project, it is possible to determine similarities among risk events and classify them within them. These events will constitute the aspects to be assessed within the risk model of the Project, considering the performance, timeline and associated costs to the different alternatives. According to [3], the criteria of level of probability of occurrence, $P_{i}$, are applied to the levels presented in Table 1. 
Table 1. Criteria of level of probability of occurrence, Pi

\begin{tabular}{|c|c|}
\hline LEVEL & DESCRIPTION \\
\hline 0.1 & Remote \\
\hline 0.3 & Improbable \\
\hline 0.5 & Probable \\
\hline 0.7 & Highly probable \\
\hline 0,9 & Almost surely \\
\hline
\end{tabular}

In the same way, the level of impact $\left(C_{i}\right)$ for each risk event is considered in a scales that varies between 0,1 (minimum) and 0.9 (unacceptable).

Finally, to obtain the OMOR, the values for the MOPs associated to the risks that impact the development of the project are extracted from the effectiveness model. Later, the pairs are compared to obtain a relevance relationship between the risks associated to performance, timeline, and cost. This comparison defines the importance of each one of these three measurements associated to the total measurement of risk, which is finally obtained in function of the following equation 2 .

$$
\begin{aligned}
\text { OMOR }= & W_{\text {perf }} \frac{\sum_{i} P_{i} C_{i} \cdot w_{i}}{\sum_{i}\left(P_{i} C_{i}\right)_{\max } \cdot \sum_{i} w_{i}} \\
& +\frac{\sum_{j} P_{j} C_{j}}{\sum_{j}\left(P_{j} C_{j}\right)_{\max }}+W_{\text {sched }} \frac{\sum_{k} P_{k} C_{k}}{\sum_{k}\left(P_{k} C_{k}\right)_{\max }}
\end{aligned}
$$

Where:

$i$ : Risks associated to performance

$j$ : Risks associated to cost

$k$ : Risks associated to timeline

$P$ : Probability of occurrence

$C$ : Impact

$W:$ Ponderation of the type of risk

$w$ : Ponderation of the risk associated to performance

\section{Cost Model}

The general measurement for cost or OMOC, is used to analyze the different alternatives and evaluate the costs required by COTECMAR-ARC. This model does not intend to forecast a final cost value for the project, since it is not a cost estimation exercise, however, the activities for each alternative are evaluated according to their associated cost. In the same way, to generate the model, both direct and indirect costs are analyzed and three main levels are established for evaluation:

\section{Association Cost $\left(C_{a}\right)$}

Direct cost of the association required for the development of the Project. Includes the cost related to goods and services, taxes and nationalization.

\section{Cost of participation $\left(C_{p}\right)$}

Direct and indirect costs associated to the contribution of COTECMAR-ARC to fulfill the work schedule, equipment delivery plan, training, on-site work training and development process.

Likewise, the costs associated to the technology transfer process are considered and those that allow for the comparative analysis between the different proposals. An analysis is made for the following costs:

- Personnel:

Associated to the staff that participates in the development activities and transfer of technology. The estimation of this value is done, considering the number of people, number of days and location.

$C_{p p}=f_{p l}\left(\left[n_{p}, n_{t}\right],\left[t_{p}, t_{t}\right]\right)+f_{p n}\left(\left[n_{p}, n_{t}\right],\left[t_{p}, t_{t}\right]\right)$

$+f_{p e}\left(\left[n_{p}, n_{t}\right],\left[t_{p}, t_{t}\right]\right)$

Where:

$C_{p p}$ : Cost of participation personnel category

$f_{p l}^{p p}$ Cost of local participation.

$f_{p n}$ : Cost of participation at a national level out of the city of origin.

$f_{p e}:$ Cost of participation abroad.

$n$ : number of people that participate ( $\mathrm{p}$ : professional, t: technical).

$t$ : duration time of participation.

$z$ : area where the activities are to be developed (only abroad) 


\section{- Initial training:}

Preparation of the staff that participates in the process of technology transfer during the development of a project. To calculate the cost of this training, average market values are used to cover the area of interest.

\section{- Hardware and Software:}

Correspond to the use of computer equipment and software during the technology transfer activities.

\section{Cost of life cycle $\left(C_{v}\right)$}

Costs projected in time, associated to activities resulting from the process of technology transfer. These costs must be projected along the entire life cycle of the system and represented in present value. The costs associated to the use cycle ${ }^{2}$ of the naval system to be developed and the maintenance costs $\left(C_{m}\right)$ and training costs $\left(C_{e}\right)$ are identified as the most relevant to calculate the OMOC. Although this analysis doesn't only include these cost areas, they are considered the most relevant capacities to acquire through technological transfer and allow to indicate significant changes among the different alternatives.

The cost of life cycle $\left(C_{v}\right)$, is expressed as:

$$
C_{v}=C_{m}+C_{e}
$$

- Maintenance $\left(C_{m}\right)$ :

Maintenance activities are classified into 5 different levels according to the degree of intervention in the system and the maintenance classification specified in [5]. The associated cost to each level corresponds to the amount of work hours associated to maintenance activities, frequency for this type of maintenance and vale of hour per person. To assess maintenance, the percentage of capacity is specified from each one of the maintenance levels.

$$
C_{m i}=\left(Q_{m} * C_{m l}+\left(1-Q_{m}\right) * C_{m e}\right) * f * t
$$

Where:

\footnotetext{
2 Generally, the life cycle of a system may be described in the design, production, commercialization, use and dismantling stages.
}

$C_{m i}:$ Cost associated to maintenance in level $i$

$Q_{m}$ : Acquired maintenance Capacity

$C_{m l}:$ Cost of local workforce

$C_{m e}$ : Cost of external workforce

$f$ : Yearly frequency of the maintenance cycle

$t$ : Duration of maintenance operations

Finally the maintenance cost is calculated $C_{m}$ as the addition of the cost of the 5 levels.

$C_{m}{ }^{\prime}=\sum_{i=1}^{5} C_{m i}$

This cost, projected to the number of years in the useful lifecycle is transferred to present value, with a profitability equal to the average DTF for the past years, and it is shown in Equation 7.

$C_{m}=\sum_{p=0}^{a} C_{m}^{\prime} *(z)^{p}$

$z$ : factor dependent on the number of years (a) and inflation.

- Training $\left(C_{e}\right)$ :

The level of obtained capabilities is used, by estimating the costs associated to training, in this case, the level of capabilities acquired to render future training throughout the lifecycle of the system, in three different levels of training: basic, intermediate and expert.

For the specific case of the applied project, it is represented by a linear equation of the training costs in function of time $f(t)$. This way, the cost of training done by an external agent is expressed as:

$C_{e e i}=f(t) * n * F$

Where

$C_{\text {eei }}$ : Annual cost of training by an external agent in the i- est level

$t$ : Training duration

$n$ : Number of people trained

$F$ : Annual training frequency 
The final assessment of this measurement is expressed as follows:

$C_{e i}\left(Q_{e}\right)=\sum_{1}^{l}\left(Q_{e} * C_{e l i}+\left(1-Q_{e}\right) * C_{e e i}\right)$

Where:

$Q_{i}$ : Acquired Capability to conduct training at the i- est level

l: Number of training levels

This cost is projected to a specific number of years and brought to present value.

$$
C_{e}=\sum_{p=0}^{a} C_{e}{ }^{\prime} *(z)^{p}
$$

$z$ : factor dependent on the specific number of years (a) and inflation.

The calculation of OMOC is done through the arithmetic addition of each one of the types of costs described:

$$
\text { OMOC }=C_{a}+C_{p}+C_{v}
$$

\section{Application of the model}

To obtain the results from the application of the model, five (5) possible scenarios are designed, where each alternative is evaluated and the obtained ponderations are analyzed. Each assessment offers an aid in decision making considering the available budget and the capabilities that COTECMARARC aims to obtain.

Likewise, a desirable range for each one of the measurements of effectiveness, risk and costs is determined, thus filtering the alternatives that do not comply with the following restrictions:

- Effectiveness: obtained value higher than $60 \%$

- Cost: between $20 \%$ and $40 \%$ of the available Budget for the association.

- At Risk: medium, low and very low risk index.

For the risk index, four ranges are set: Very low (less than 25\%), low (26\% - 50\%), medium $(51 \%$ 75\%), high (higher than 75\%)

Fig. 5 presents the results of the alternatives assessed in the different proposed scenarios which comply with the established restrictions. The graph shows the effectiveness value in the vertical axis, a cost value in the horizontal axis, provided as a percentage related to the highest cost activity and a risk value represented by a color associated to its ponderation.

The highlighted points in the dotted area, show the options that have a higher possibility to be selected because they represent an effectiveness-cost-risk relationship that is favorable and valid to develop the project.

It is noteworthy to state that this model and the results obtained from the assessment, offer great help for decision-making, however, the selection of the alternative is done in function of the analysis of correlation between OMOE, OMOR and OMOC.

\section{Conclusions}

The application of the methodology for the design of assessment models presented in this document, results in a reduced Group of alternatives which best adjust to the Budget, risk and desired scope conditions, for the execution of projects, making it easier to make decisions that aim to acquire the capabilities of development of naval systems at ARC-COTECMAR.

The effectiveness, cost, and risk are observed as different attributes that use different measurement units, for which they cannot be rationally combined to produce one sole objective function.

This entails that they are presented individually but simultaneously, in an easily manageable format that allows for interaction between them, easing decision-making.

This format is a space for selection, where the alternatives may be graphed out as points, using the values obtained for effectiveness, cost and risk 
Fig. 5. Selection Alternatives

OMOE - OMOC - OMOR

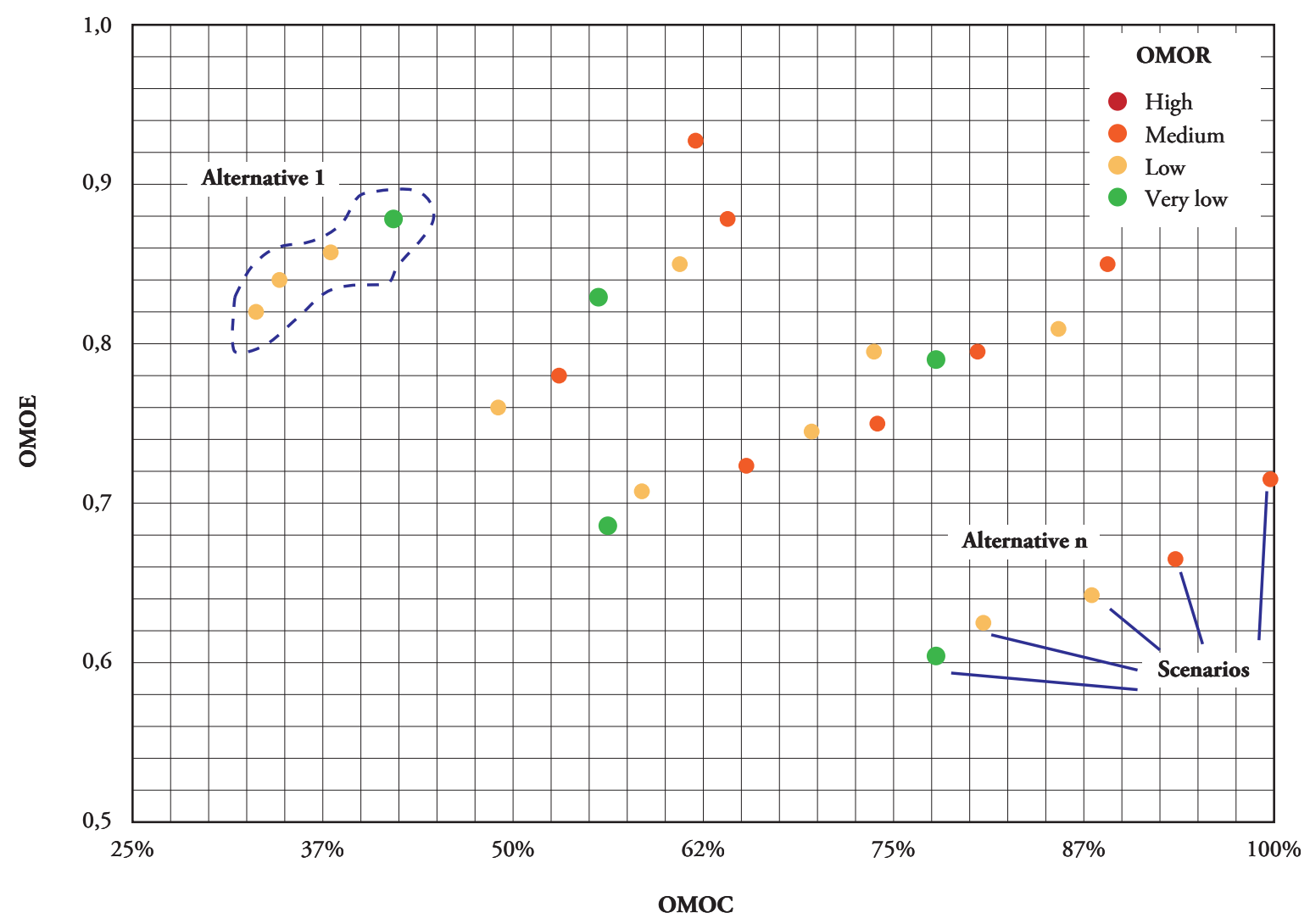

as coordinates, thus offering a perspective that aids at the moment of decision-making.

In general, the methodology proposed by [2] and [3] may be applied to any type of Project, considering the different measures and factors to evaluate, taking into account the risk and cost in the development and the nature of the project.

\section{Bibliographical References}

[1] COTECMAR - ARC. Metodología de evaluación para selección del aliado tecnológico. Codesarrollo de un sistema de red táctica naval para la Armada Nacional de Colombia. (Evaluation Methodology For Choosing a Technological Ally) .Cartagena, Colombia. Clasificación: Secreto. Marzo 2015.
[2] J. Carreño, A. Del Gordo, J. Jimenezy O. Tascón. Desarrollo de una Metodología de Soporte para la Toma Racional de Decisiones en la Adquisición de Buques (Development of a Support Methodology for Rational Decision Makingin Ship Acquisition). Bogotá: ESDEGUE- CEM, 2007.

[3] J. Gómez y O. Tascón. "Methodology for analysis and evaluation of alternatives during warship conceptual design". NEJ vol. 116, pp. 5572. Abril. 2004.

[4] A. Brown y T. Mierzwicki. "Risk Metric for Multi-Objective Design of Naval Ships”. NEJ vol. 116, pp. 55-72. Abril. 2004.

[5] AFNOR, FD X 60-000, ISSN 0335-3931, Francia, Mayo 2002. 